\title{
NTP42, a novel antagonist of the thromboxane receptor, attenuates experimentally induced pulmonary arterial hypertension
}

Eamon P. Mulvaney ${ }^{1}$, Helen M. Reid ${ }^{1,2}$, Lucia Bialesova ${ }^{1}$, Annie Bouchard ${ }^{3}$, Dany Salvail ${ }^{3}$ and

B. Therese Kinsella ${ }^{1,2^{*}}$ (D)

\begin{abstract}
Background: NTP42 is a novel antagonist of the thromboxane prostanoid receptor (TP), currently in development for the treatment of pulmonary arterial hypertension (PAH). PAH is a devastating disease with multiple pathophysiological hallmarks including excessive pulmonary vasoconstriction, vascular remodelling, inflammation, fibrosis, in situ thrombosis and right ventricular hypertrophy. Signalling through the TP, thromboxane (TX) $A_{2}$ is a potent vasoconstrictor and mediator of platelet aggregation. It is also a pro-mitogenic, pro-inflammatory and pro-fibrotic agent. Moreover, the TP also mediates the adverse actions of the isoprostane 8-iso-prostaglandin $\mathrm{F}_{2 a}$ a free-radical-derived product of arachidonic acid produced in abundance during oxidative injury. Mechanistically, TP antagonists should treat most of the hallmarks of PAH, including inhibiting the excessive vasoconstriction and pulmonary artery remodelling, in situ thrombosis, inflammation and fibrosis. This study aimed to investigate the efficacy of NTP42 in the monocrotaline (MCT)-induced PAH rat model, alongside current standard-of-care drugs.
\end{abstract}

Methods: PAH was induced by subcutaneous injection of $60 \mathrm{mg} / \mathrm{kg} \mathrm{MCT} \mathrm{in} \mathrm{male} \mathrm{Wistar-Kyoto} \mathrm{rats.} \mathrm{Animals} \mathrm{were} \mathrm{assigned}$ into groups: 1. 'No MCT'; 2. 'MCT Only'; 3. MCT + NTP42 (0.25 mg/kg BID); 4. MCT + Sildenafil (50 mg/kg BID), and 5. MCT + Selexipag (1 mg/kg BID), where 28-day drug treatment was initiated within $24 \mathrm{~h}$ post-MCT.

Results: From haemodynamic assessments, NTP42 reduced the MCT-induced PAH, including mean pulmonary arterial pressure (mPAP) and right systolic ventricular pressure (RSVP), being at least comparable to the standardof-care drugs Sildenafil or Selexipag in bringing about these effects. Moreover, NTP42 was superior to Sildenafil and Selexipag in significantly reducing pulmonary vascular remodelling, inflammatory mast cell infiltration and fibrosis in MCT-treated animals.

\footnotetext{
* Correspondence: therese.kinsella@atxatherapeutics.com

'ATXA Therapeutics Limited, UCD Conway Institute of Biomolecular and Biomedical Research, University College Dublin, Belfield, Dublin 4, Ireland ${ }^{2}$ UCD School of Biomolecular and Biomedical Sciences, UCD Conway Institute of Biomolecular and Biomedical Research, University College Dublin, Belfield, Dublin 4, Ireland

Full list of author information is available at the end of the article
}

(c) The Author(s). 2020 Open Access This article is licensed under a Creative Commons Attribution 4.0 International License, which permits use, sharing, adaptation, distribution and reproduction in any medium or format, as long as you give appropriate credit to the original author(s) and the source, provide a link to the Creative Commons licence, and indicate if changes were made. The images or other third party material in this article are included in the article's Creative Commons licence, unless indicated otherwise in a credit line to the material. If material is not included in the article's Creative Commons licence and your intended use is not permitted by statutory regulation or exceeds the permitted use, you will need to obtain permission directly from the copyright holder. To view a copy of this licence, visit http://creativecommons.org/licenses/by/4.0/. The Creative Commons Public Domain Dedication waiver (http://creativecommons.org/publicdomain/zero/1.0/) applies to the data made available in this article, unless otherwise stated in a credit line to the data. 
(Continued from previous page)

Conclusions: These findings suggest that NTP42 and antagonism of the TP signalling pathway have a relevant role in alleviating the pathophysiology of $\mathrm{PAH}$, representing a novel therapeutic target with marked benefits over existing standard-of-care therapies.

Keywords: Thromboxane, Prostanoid, Thromboxane receptor antagonist, Pulmonary arterial hypertension, PAH, Monocrotaline, NTP42

\section{Background}

Pulmonary arterial hypertension (PAH) is a chronic progressive disorder of the pulmonary vasculature characterised by abnormal remodelling of small, peripheral resistance vessels in the lung. The occlusion of these pulmonary arterioles leads to a persistently elevated pulmonary vascular resistance (PVR), a raised pulmonary arterial pressure (PAP), and ultimately death due to right ventricular hypertrophy, decreased cardiac output and heart failure. Since the recent 2018 World Symposium on Pulmonary Hypertension, PAH is defined haemodynamically by the presence of mean PAP (mPAP) $>20 \mathrm{mmHg}$ alongside an elevated PVR $\geq 3$ Wood Units [1]. The underlying pathological hallmarks of $\mathrm{PAH}$ include pulmonary arterial endothelial cell (EC) dysfunction, excessive vasoconstriction, pulmonary artery EC and smooth muscle cell (SMC) proliferation, inflammation \& fibrosis, in situ thrombosis and right ventricular (RV) hypertrophy.

Currently, PAH is primarily treated with drugs from four major drug classes targeting the endothelin, prostacyclin and nitric oxide (NO) signalling pathways. However, these approved therapies mainly treat the excessive pulmonary vasoconstriction/reduced vasodilation but fail to alter the cardiac and pulmonary remodelling associated with the later phases of the disease. Therefore, there is an urgent unmet medical need for new drugs to new therapeutic targets that offer greater tolerability/compliance and overall efficacy.

An exciting alternative approach to achieving improved vasodilation is to reduce the excessive vasoconstriction by antagonizing/inhibiting the action of the prostanoid thromboxane (TX) $\mathrm{A}_{2}$. TXA $\mathrm{TX}_{2}$, synthesised from arachidonic acid (AA) by the sequential actions of cyclooxygenase (COX)-1/ COX-2 and TXA $_{2}$ synthase $\left(\mathrm{TXA}_{2} \mathrm{~S}\right)$, mediates its actions in humans by binding to the TP $\alpha$ and TP $\beta$ isoforms of the T Prostanoid receptor (the TP). $\mathrm{TXA}_{2}$ is a potent mediator of platelet aggregation and induces constriction of various types of smooth muscle (SM) including vascular, renal and pulmonary SM. In addition, TXA $_{2}$ acts as a potent pro-inflammatory and pro-mitogenic agent promoting inflammation, fibrosis, blood vessel remodelling and/or restenosis following endothelial injury and is the main COX-derived SM constrictory prostanoid produced within the lung [2-5]. Hence, imbalances in the levels of $\mathrm{TXA}_{2}$, or of $\mathrm{TXA}_{2} \mathrm{~S}$ or of the TP have been implicated in a range of cardiovascular, renal and pulmonary diseases, including in PAH [2-5]. The $\mathrm{TXA}_{2}$-TP axis also regulates key mitogenic/ERK and RhoA-mediated signalling cascades, explaining, at least in part, the role of $\mathrm{TXA}_{2}$ in increasing cell proliferation and migration such as occurs in restenosis, vascular remodelling, and in a range of cancers in which the TXA $\mathrm{T}_{2}$-TP axis is increasingly implicated [2-8].

Moreover, and also critically, the TP not only mediates the actions of $\mathrm{TXA}_{2}$ but also those of the isoprostane 8-isoprostaglandin (PG) $\mathrm{F}_{2 \alpha}$ (also termed 15-F2t-isoprostane), a non-enzymatic-, free-radical- derived product of arachidonic acid produced in abundance during oxidative injury/hypoxia, including in various cardiovascular and pulmonary diseases [9]. Significantly in the context of $\mathrm{PAH}, 8$-iso- $\mathrm{PGF}_{2 \alpha}$ is increased over 3-fold in $\mathrm{PAH}$ patients and correlates with PAH status and disease progression $[2,9,10]$. A recent study has also demonstrated the pivotal role of 8 -iso- $\mathrm{PGF}_{2 \alpha}$ signalling through the TP in the pathogenesis of pulmonary fibrosis [11], a key hallmark of PAH disease progression. Thus, TP antagonists will have benefits over existing PAH therapies in that they will not only inhibit the adverse actions of $\mathrm{TXA}_{2}$ itself but also those of 8 -iso- $\mathrm{PGF}_{2 \alpha}$ which is present in high amounts in the hypoxic environ of the PAH lung [10].

As further evidence of its role in $\mathrm{PAH}, \mathrm{TXA}_{2}$ or its stable analogues are also used widely to induce pulmonary hypertension $(\mathrm{PH})$ in large preclinical animal models such as the pig [12]. Infusion of the $\mathrm{TXA}_{2}$ mimetic U46619 results in stable $\mathrm{PH}$, with significant increases in mPAP, PVR and in cardiac output (CO) [12-14]. Furthermore, within a hypoxia-induced $\mathrm{PH}$ model in pigs, disruption of $\mathrm{TXA}_{2}$ production and TP signalling attenuates the negative effects on pulmonary and cardiac parameters [15]. Following treatment with the TP antagonist Daltroban, the significant hypoxia-induced rises in mPAP, PVR and mean right atrial pressure were significantly reduced [15].

NTP42 is a novel antagonist of the TP and is currently in development for the treatment of PAH. During its development, over 250 small chemical compounds were characterised in calcium mobilisation assays in human embryonic kidney (HEK) 293 cells over-expressing TP $\alpha$ and TP $\beta$ following stimulation with the $\mathrm{TXA}_{2}$ mimetic U46619 or the isoprostane 8 -iso- $\mathrm{PGF}_{2 \alpha}[16,17]$. Following this primary screen, prioritised leads were then subject to secondary screening by examining their ability to inhibit TP (U46619)- mediated aggregation of human platelets ex vivo 
$[16,17]$. Key leads in this series, including the drug candidate NTP42, were confirmed to display potent antagonist activity, excellent specificity, pharmacokinetic, pharmacodynamic, toxicology and efficacy profiles in a range of in vitro, ex vivo and in vivo pre-clinical models following oral delivery [16, 17]. Mechanistically, TP antagonists such as NTP42 may be promising therapeutic drugs for $\mathrm{PAH}$, not only inhibiting the excessive vasoconstriction but also preventing the micro-vessel thrombosis and, potentially, limiting the pulmonary artery remodelling, as well as the inflammation and fibrosis found in PAH. In addition, as also stated, TP antagonists will inhibit signalling by 8 -iso- $\mathrm{PGF}_{2 \alpha}$, the freeradical derived isoprostane generated in abundance in the clinical setting of PAH [2,9-11]. Thus, the aim of this study was to investigate the efficacy of NTP42 in the monocrotaline (MCT)-induced PAH rat model, alongside current standard-of-care compounds.

\section{Methods}

\section{Human lung tissue}

Lung tissue from patients with PAH and control subjects was obtained from the Royal Papworth Hospital NHS Foundation Trust Tissue Bank (Cambridge, UK). Patients $(n=12)$ had received lung or heart/lung transplantation for $\mathrm{PAH}$ and tissue samples were confirmed to display pathology in keeping with $\mathrm{PAH}$. Control lung $(n=12)$ comprised tissue taken from pneumonectomy specimens resected for malignancy, but distant from tumour regions. Written consent was obtained for all tissue samples using Royal Papworth Hospital NHS Foundation Trust Tissue Bank's ethical approval (East of England - Cambridge East Research Ethics Committee 08/H0304/56 + 5). Haematoxylin and eosin (H\&E) and immunohistochemical staining for the TP $\alpha$ and TP $\beta$ isoforms of the $\mathrm{T}$ Prostanoid receptor (TP) and the I Prostanoid receptor (IP) was subsequently carried out on each section, as detailed in the Supplementary materials.

\section{Experimental design of preclinical animal studies}

All animal studies were performed at the specificpathogen-free (SPF) facilities of IPS Therapeutique (IPST; Sherbrooke, Quebec, Canada). The institutional animal ethics committee of IPST approved the studies in strict accordance with the guidelines of the Canadian Council on Animal Care and the US NIH Guide for the Care and Use of Laboratory Animals. Male WistarKyoto rats (Charles River Laboratories, St Constant, Quebec, Canada), aged between 8 and 9 weeks and weighing $200-250 \mathrm{~g}$ at the time of their enrolment in the studies were randomised according to their body weight into 5 groups (Groups 1-5) spanning two experimental cohorts (Cohorts \#1 and \#2; see Supplemental Table 1A for composition of animal groups and experimental cohorts). Animals in Groups 2 to 5 received a single dosage of monocrotaline (MCT; $30 \mathrm{mg} / \mathrm{ml}$ stock, in DMSO) by subcutaneous injection at $60 \mathrm{mg} / \mathrm{kg}$ dosage on the morning of Day 0. Animals in Group 1 received one subcutaneous injection of the MCT vehicle (DMSO; $2 \mathrm{ml} / \mathrm{kg}$ ) on the morning of Day 0. Drug treatments were initiated on Day 1 and continued until Day 28. During this period, animals were treated twice-daily (BID) by oral gavage (PO) with NTP42 $(0.25 \mathrm{mg} / \mathrm{kg}$ BID, Group 3), Sildenafil (50 mg/kg BID, Group 4), Selexipag (0.25 $\mathrm{mg} / \mathrm{kg}$ BID, Group 5) or, as negative controls, with drug vehicle (0.375\% DMSO; Groups 1 and 2). In all cases, drugs/vehicle were delivered in a dosing volume of $2 \mathrm{ml}$ (BID, PO), where drug treatment began within $24 \mathrm{~h}$ post-MCT administration. During the treatment period, rats were given food and water ad libitum. The animals were pair-housed for the duration of the study. All animal care and vivarium maintenance were recorded, with documents kept at the test facility. In addition, clinical observations or cage-side parameters were also recorded throughout the study including food and water intake, breathing activity levels, clinical signs of distress, general well-being, etc. and changes in body weight. All procedures were performed under isoflurane-induced, inhalational anaesthesia to minimize suffering. At the end of the study, following haemodynamic evaluations, animals under anaesthesia were euthanised by exsanguination.

\section{Haemodynamic evaluations}

At the end of the treatment period, on the afternoon of Day 28 of treatment, animals were anesthetised with a mixture of 2-2.5\% isoflurane (Abbott Laboratories, Montreal, Canada) in $95 \% \mathrm{O}_{2} / 5 \% \mathrm{CO}_{2}$, and placed on a heating pad to maintain body temperature. Rats were then tracheotomised and immediately ventilated by means of a positive-pressure rodent respirator set at $10 \mathrm{ml} / \mathrm{kg}$ body weight at a frequency of 65-70 strokes/ min. A cannula connected to a pressure transducer was inserted into the left femoral artery to measure the systemic arterial blood pressure. Lead II electrocardiogram (ECG) contact electrodes were placed on the rats to continuously monitor the ECG and a pulse oximeter was placed on the left front paw of the animal to measure oxygen saturation. ECG and saturation were monitored continuously during the surgery. The heart was exposed through a sternotomy and a $20 \mathrm{G} 30 \mathrm{~mm}$ Insyte catheter was introduced into the right ventricle (RV) and rapidly hooked up to a saline filled PE-50 catheter connected to a pressure transducer. Following recording of the right ventricular pressure, the catheter was advanced through the pulmonary valve into the pulmonary artery to allow pulmonary pressure recording. Correct positioning of the catheter was achieved by observing clear transitions in diastolic pressures and general pressure waveforms as the catheter transitioned from the ventricle into the 
artery. Haemodynamic parameters were recorded continuously for the duration of the procedure or until loss of pulmonary arterial pressure signal. Diastolic and systolic pressure values were measured in $\mathrm{mmHg}$ using cursors readings in Clampfit 10.2.0.14 module of the pClamp 10.2.0.14 software (Molecular Devices Inc., Foster City, California, USA). Mean systemic or pulmonary arterial pressure values were calculated using the following formula: Mean Pressure $=$ Diastolic Pressure $+1 /$ $3 \times$ (Systolic Pressure - Diastolic Pressure). Animal groups were randomized with the aim of scheduling at least one animal per group for each day of terminal surgery.

\section{Tissue preparation}

Following haemodynamic evaluations, the animal was euthanised by exsanguination, the pulmonary circulation was flushed with $0.9 \% \mathrm{NaCl}$, and the heart and lungs were removed en bloc from the thoracic cavity. The cardiac tissue was dissected to measure the wet weights of the RV and left ventricle including the septum $(L V+S)$ as part of the Fulton's index for determination of RV hypertrophy. The left lung lobes were fixed in formalin, dissected into blocks from each of the lower, middle and upper regions and processed to formalin-fixed paraffinembedded (FFPE) tissue blocks.

\section{Pulmonary histology and vascular morphometry}

FFPE tissue blocks from the middle regions of the left lungs from both Cohorts \#1 \& \#2 were subject to sectioning to yield $4 \mu \mathrm{m}$ sections and stained with $\mathrm{H} \& \mathrm{E}$ to facilitate histological assessment and morphometric analysis to evaluate vascular remodelling. H\&E-stained tissue sections were scanned at 40X magnification using the Aperio Slide Scanner ScanScope XT and viewed using QuPath software [18]. Morphometric analysis was subsequently carried out on each section, where measurements for the total and lumen vessel diameter for all arterioles of diameter $\geq$ $15 \mu \mathrm{m}$ present in 10 randomly-selected fields/section (10 $\mathrm{mm}^{2}$ total tissue area) were recorded, essentially as previously described [19] and as detailed in full in the Supplementary materials. Based on these measurements, values for the lumen:total ratio, medial thickness $(\mu \mathrm{m})$ and degree of vessel occlusion (\%) were calculated. All analyses were carried out in a blinded fashion with overlap by three independent observers.

\section{Mast cell counting}

For assessment of mast cell density, FFPE tissue blocks from the middle regions of the left lungs from Cohort \#2 only were sectioned $(4 \mu \mathrm{m})$ and stained with toluidine blue $(0.1 \% \mathrm{w} / \mathrm{v})$. Toluidine blue-stained tissue sections were scanned at $40 \mathrm{X}$ magnification using the Aperio Slide Scanner ScanScope XT. Slides were viewed in
QuPath [18], where an annotation was demarcated comprising the entire tissue area, with the major bronchial and vascular regions removed. Toluidine blue-positive mast cells were counted across the entire annotation using the Fiji distribution of NIH ImageJ software [20] and where values are reported as the number of mast cells per $\mathrm{mm}^{2}$.

\section{Pulmonary fibrosis analysis}

FFPE tissue blocks from the middle regions of the left lungs from Cohort \#2 only were sectioned $(4 \mu \mathrm{m})$ and stained with Masson's trichrome connective tissue staining kit, according to the manufacturer's instructions (ab150686; Abcam). Trichrome-stained tissue sections were scanned at $40 \mathrm{X}$ magnification using the Aperio Slide Scanner ScanScope XT. Slides were viewed in QuPath [18], where an annotation was demarcated comprising the entire tissue area, with the major bronchial and vascular regions removed. The percentage fibrotic area was determined in each section using the Fiji distribution of NIH ImageJ software [20] where images were first subjected to colour deconvolution to separate the collagen (blue) staining channel, essentially as previously described [21].

\section{Statistical analysis}

In all cases, potential outliers within each data set were identified based on the method of interquartile range (IQR) with Tukey fences, to exclude values falling outside either; (i) [Quartile 1 (Q1) - 1.5*IQR] (Lower Fence), or, (ii) [Quartile $3(\mathrm{Q} 1)+1.5 * \mathrm{IQR}]$ (Upper Fence). Statistical analyses of differences were then carried out using unpaired Student's t-tests or one-way ANOVA, followed by post-hoc Dunnett's multiple comparison t-tests where appropriate, employing GraphPad Prism (V6) throughout. All values are expressed as the mean \pm standard error of the mean (SEM) and $n$ numbers are detailed within the corresponding figure legend. $P$ values $\leq 0.05$ were considered to indicate statistically significant differences, where $*{ }^{*}{ }^{* * * * * * *}$ and ${ }^{* * * * *}$ denote $P \leq 0.05,0.01,0.001$, and 0.0001 , respectively.

\section{Results}

Expression of the TP in human control and PAH lung tissue

While signalling through the thromboxane receptor (TP) is implicated in the pathogenesis and progression of $\mathrm{PAH}$, few studies have examined the expression of the TP in human PAH lung tissue. Herein, the expression of the TP $\alpha$ and TP $\beta$ isoforms of the TP was examined in lung tissue from control individuals and $\mathrm{PAH}$ patients (Fig. 1). As a control, expression of the prostacyclin receptor (IP), a related existing PAH drug target, was also investigated. 

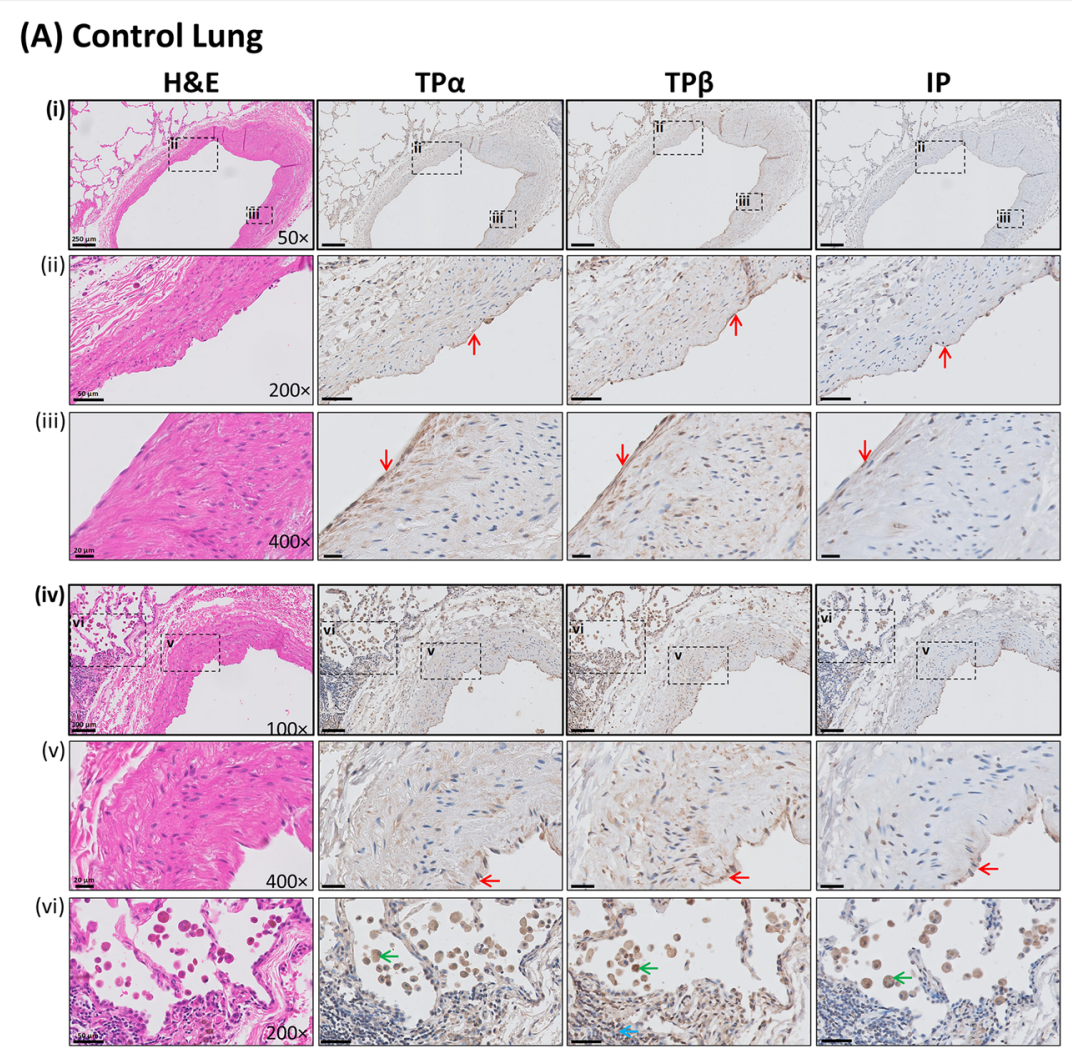

(B) PAH Lung
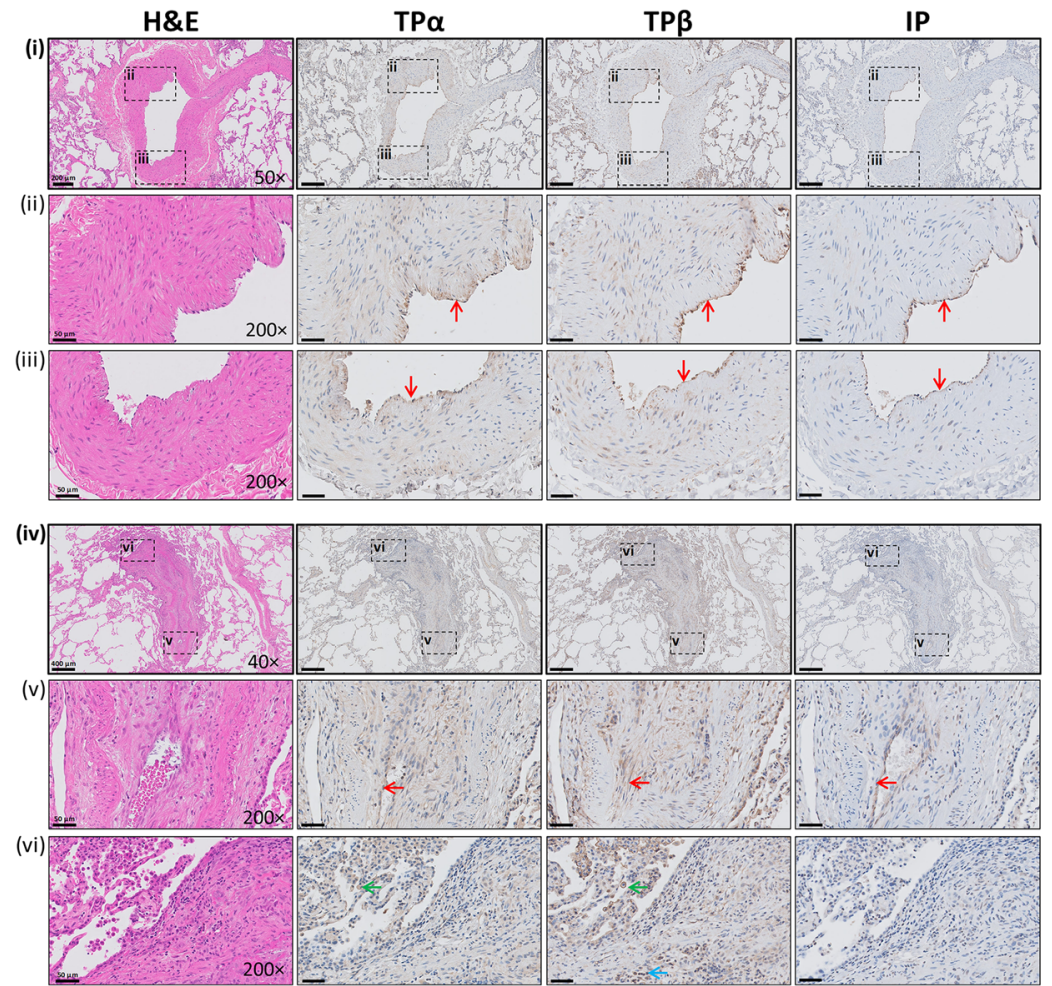

Fig. 1 (See legend on next page.) 
(See figure on previous page.)

Fig. 1 Expression of the IP and TPa/TPB in control and PAH lung tissue. Representative photomicrographs of haematoxylin and eosin (H\&E) and immunohistochemical staining for I Prostanoid (IP) and both TPa and TP $\beta$ isoforms of the T Prostanoid receptor (TP), in lungs isolated from (a) control individuals and (b) PAH patients. In both Panel A and Panel B, macro images of pulmonary arteries are shown in subpanels (i) and (iv). To enable examination of vascular endothelial and smooth muscle staining, higher magnifications of the pulmonary artery wall, delineated by dotted lines in subpanels (i) and (iv), are displayed in the corresponding subpanels (ii) \& (iii) and (v) \& (vi), respectively. Within the macro image for each set of panels, black bars representing the respective scale and the magnification of the capture are also displayed. Arrows in the panels highlight example regions referred to in the text. Red arrows highlight vascular endothelium. Blue and green arrows highlight regions of inflammation and alveolar macrophages, respectively

Positive TP $\alpha$ \& TP $\beta$ expression was observed in numerous cell types in both control and PAH lung tissue (Fig. 1a \& b). Specifically, within the pulmonary arteries, TP $\alpha$ \& TP $\beta$ were strongly expressed within the vascular endothelium, in both control tissue (Fig. 1a (ii), 1a (iii)
$\mathcal{E} 1 a(v)$, indicated by arrowheads) and PAH tissue (Fig. $1 \mathrm{~b}$ (ii), $1 b$ (iii) $\& 1 b(v))$. Expression of both TP $\alpha$ \& TP $\beta$ was also observed within the smooth muscle (SM) of pulmonary arteries, in both control tissue (Fig. 1a (ii), 1a (iii) $\mathcal{E} 1 a(v)$ ) and PAH tissue (Fig. $1 \mathrm{~b}$ (ii), $1 b$ (iii) $\mathcal{E} 1 b$

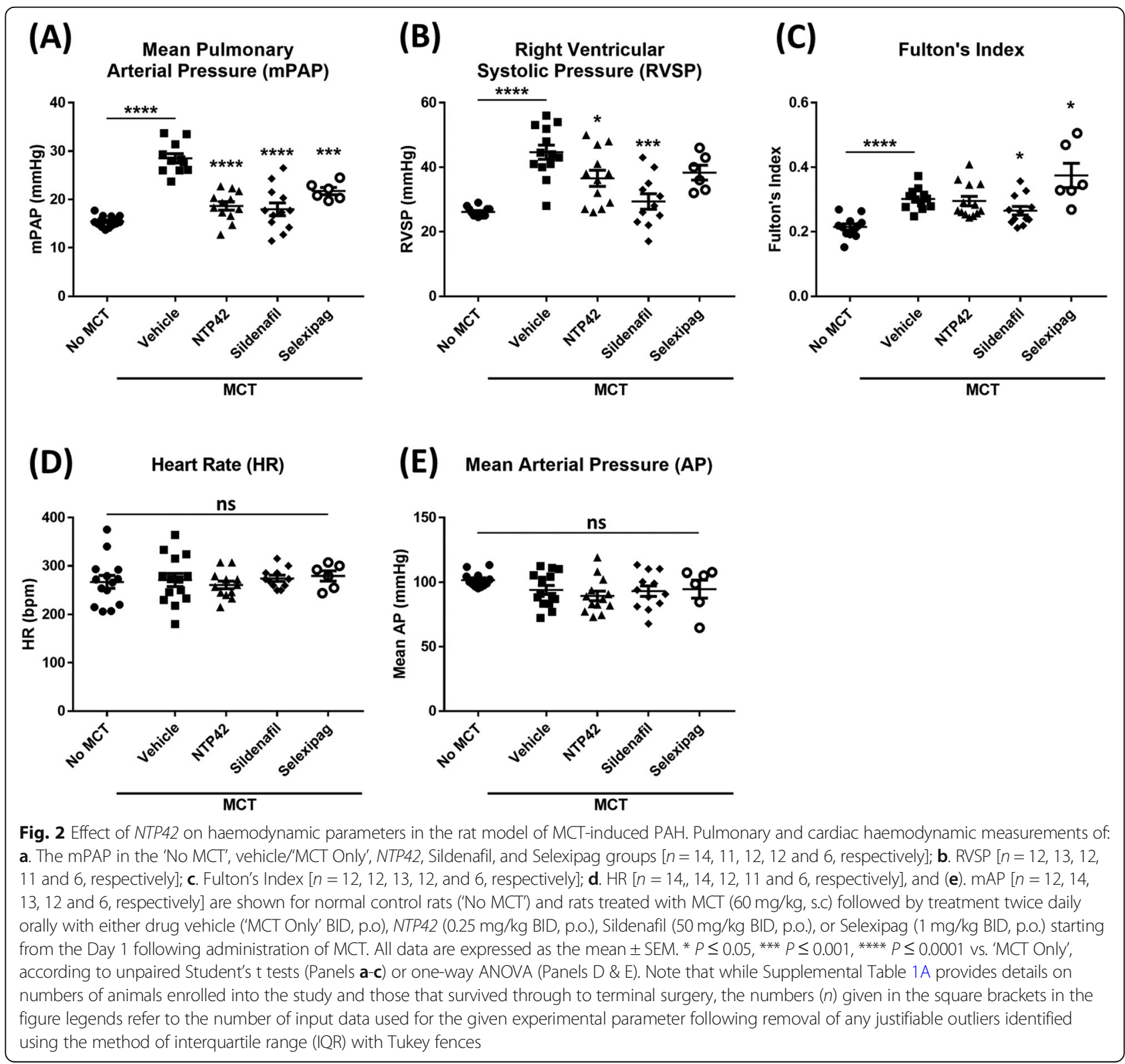


(v)). Abundant expression of TP $\alpha$ \& TP $\beta$ was also noted within plexiform lesions, the characteristic morphological hallmark of advanced PAH (Fig. 1b (iv)). These complex and disorganised networks of vascular channels result primarily from endothelial hyperproliferation, combined with increased muscularisation, inflammation and fibrosis [22]. Within these structures, TP $\alpha$ \& TP $\beta$ were expressed in the endothelial core and the surrounding SM (Fig. 1b (v)), and also in inflammatory infiltrates within and adjoining the plexiform lesion (Fig. 1b (vi)). Furthermore, within immune cells of inflammatory infiltrates in both control and PAH lungs, while predominantly negative for expression of TP $\alpha$, these infiltrates showed abundant expression of TP $\beta$ (Fig. 1a (vi) \& $1 b$ (vi), indicated by arrowheads). Additionally, strong expression of both TP $\alpha$ and TP $\beta$ was noted in alveolar macrophages (Fig. 1a (vi) \& $1 b(v i)$ ). Positive expression of the IP was primarily restricted to the vascular endothelium, being virtually absent from the vascular SM, with staining also evident in alveolar macrophages (Fig. 1a (ii), 1a (iii) \& 1a (vi), indicated by arrowheads).

Hence, these investigations demonstrate abundant expression of both TP $\alpha$ and TP $\beta$ isoforms of the TP in the human lung, both in normal control and PAH disease tissues. Bearing in mind this widespread expression of the TP within multiple cell and tissue types within the lung, these findings lend support the investigation of TP antagonism as an approach in the treatment of PAH.

\section{Effect of NTP42 on pulmonary and cardiac haemodynamics in the MCT-PAH rat model}

A gold-standard preclinical disease model for studying the effects of new drugs on the development of PAH is the monocrotaline (MCT)-induced PAH model, typically carried out in rodents. This study aimed to investigate the efficacy of the novel TP antagonist NTP42 in an MCT-induced PAH rat model. Throughout these preclinical investigations, the PAH standard-of-care drugs Sildenafil, a cGMP-specific phosphodiesterase type 5 (PDE5) inhibitor, and Selexipag, an oral prostacyclin receptor agonist, were used as reference controls.

The key pulmonary and cardiac haemodynamic findings are presented for each of the treatment groups in Fig. 2. Significant MCT-induced PAH was evidenced by increases in both the mean pulmonary arterial pressure (mPAP; compare $28.5 \pm 1.0 \mathrm{mmHg}$ in the 'MCT Only'treated group to $15.5 \pm 0.3 \mathrm{mmHg}$ for the 'No MCT' group, $P<0.0001$; Fig. 2 a) and right ventricular systolic pressure (RVSP; compare $44.7 \pm 2.2 \mathrm{mmHg}$ in the 'MCT Only'-treated group to $26.1 \pm 0.4 \mathrm{mmHg}$ for the 'No MCT' group, $P<0.0001$; Fig. $2 \mathrm{~b}$ ) without any significant change observed in either the mean systemic arterial pressure (mAP; Fig. 2d) or heart rate (HR; Fig. 2e). In addition, significant right ventricular remodelling was observed by the increase in the Fulton's index (right ventricle weight:left ventricle including the septum weight ratio; compare $0.30 \pm 0.01$ in the 'MCT Only'-treated group to $0.21 \pm 0.01$ for the 'No MCT' group, $P<0.0001$; Fig. 2c).

Following treatment with NTP42, the MCT-induced increase in the mPAP was significantly reduced (compare $18.7 \pm 0.9 \mathrm{mmHg}$ in the NTP42-treated group to $28.5 \pm$ $1.0 \mathrm{mmHg}$ for the 'MCT Only' group, $P<0.0001$; Fig. 2a). Similarly, the MCT-induced increase in RVSP was significantly reduced in NTP42-treated animals (compare $36.6 \pm$ $2.5 \mathrm{mmHg}$ in the NTP42-treated group to $44.7 \pm 2.2$ $\mathrm{mmHg}$ for the 'MCT Only' group, $P=0.0229$; Fig. 2b). There was no significant change observed in the Fulton's Index following NTP42 treatment (Fig. 2c). Similar to NTP42, both standard-of-care drugs Sildenafil and Selexipag also significantly reduced the MCT-induced increases in mPAP $(P<0.0001$ and $P=0.0003$, respectively; Fig. 2a). However, in contrast to both NTP42 and Sildenafil, treatment with Selexipag did not lead to a significant reduction in the RVSP $(P=0.0985$; Fig. $2 b)$. Furthermore, while Sildenafil treatment led to a slight improvement in the Fulton's Index ( $P=0.0332$; Fig. $2 \mathrm{c}$ ), a significant worsening in this parameter was observed following Selexipag administration $(P=0.0224$; Fig. 2c).

Taken together, these data demonstrate that NTP42 reduced the severity of MCT-induced PAH as determined from the haemodynamic measurements of mPAP and RVSP, and at least to a similar or greater extent relative to standard-of-care drugs Sildenafil or Selexipag. Importantly, while treatment with NTP42 reduced MCT-induced increases in both mPAP and RVSP, it had no deleterious effects on either the systemic mAP or HR (Fig. 2d \& e), similar to the standard-of-care drugs tested.

\section{Effect of NTP42 on pulmonary vascular remodelling in the MCT-PAH rat model}

As stated, vascular remodelling of small pulmonary arterioles is a key feature of $\mathrm{PAH}$, including in the MCT preclinical model of PAH, being a key underlying aetiology that culminates in the elevated pulmonary arterial pressure characteristic of advanced $\mathrm{PAH}$ in humans.

Representative histology images showing the morphological changes in the lung tissue from the animal groups in the MCT-PAH model, including vascular remodelling of the arterioles, are shown in Fig. 3. In animals within the 'No MCT' group, the lung tissue appears generally healthy. Specifically, animals within this group display a loose, open network of lung tissue with normal alveolar wall thickness (Fig. 3a). There is no significant vascular remodelling apparent in the small and medium pulmonary arterioles and there are no apparent sites of appreciable 


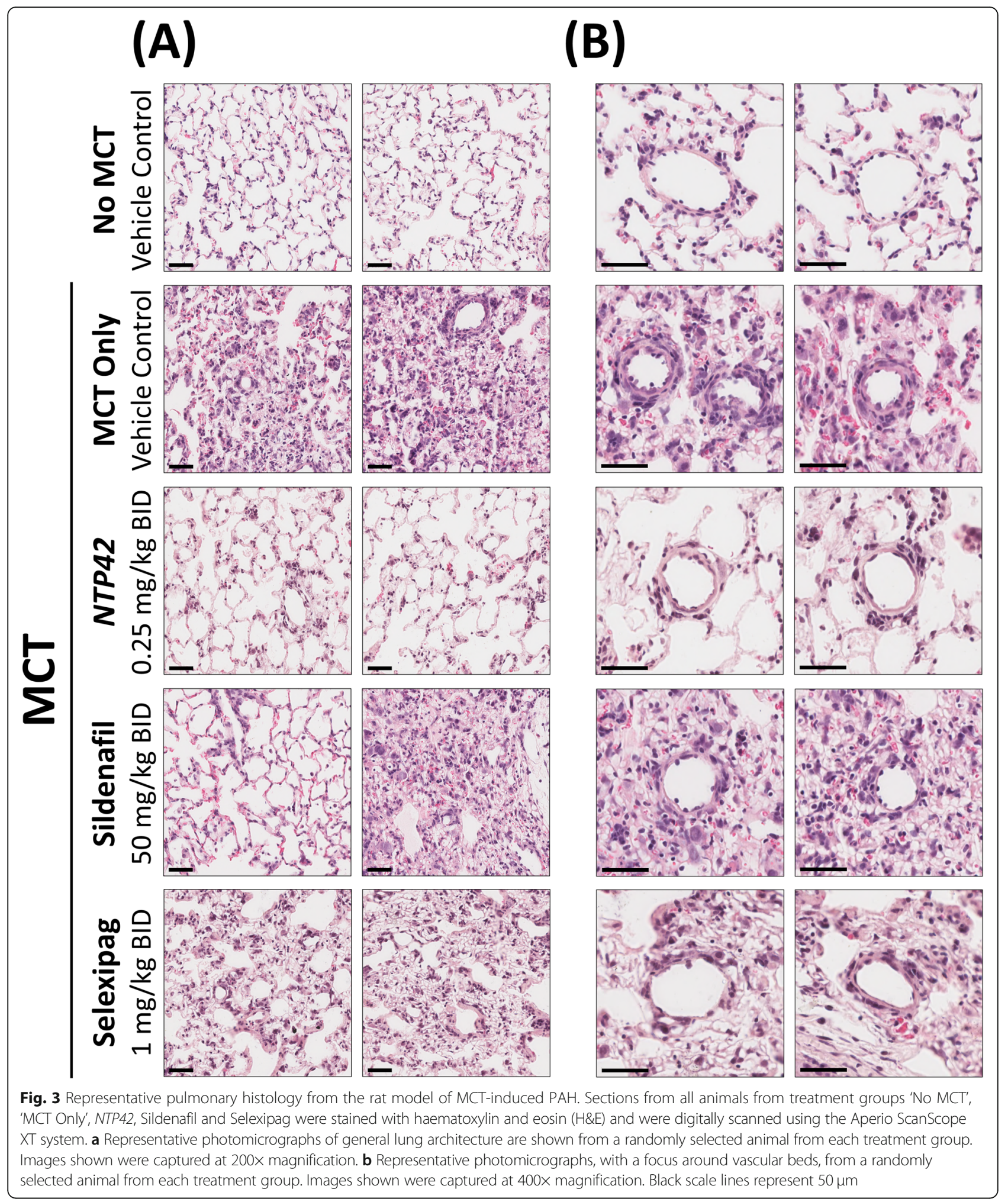

inflammatory infiltration (Fig. 3b). In contrast, animals within the 'MCT Only' group present with heavily diseased lung tissue. In these animals, the lung tissue is extremely dense in many regions with heavily thickened gas exchange distances apparent (Fig. 3a). There is a high degree of vascular thickening present, particularly in small and medium vessels, and there are multiple large instances of inflammation and oedema apparent (Fig. 3b). 


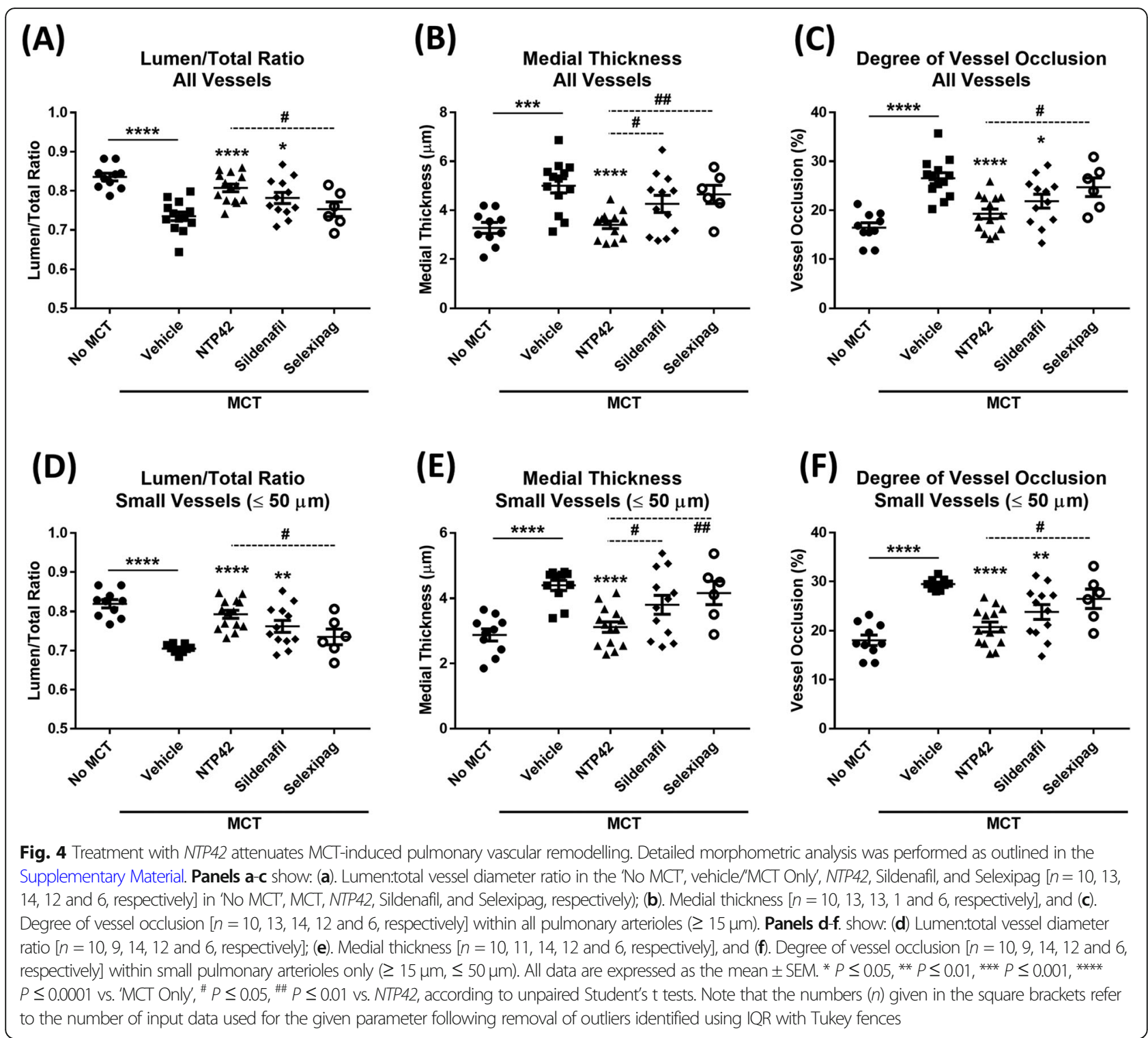

Similarly, within the Sildenafil- and Selexipagtreated animals, the lung tissue also appears quite diseased (Fig. 3). While the tissues from these animals is generally loose and open, there are multiple dense pockets with heavily thickened gas exchange distances present (Fig. 3a). There are also varying degrees of vascular remodelling apparent, in addition to small pockets of inflammation dispersed throughout the sections from these animals (Fig. 3b). In contrast, lung tissue from NTP42-treated animals appeared substantially less diseased (Fig. 3). Reminiscent of findings from the 'No MCT'- group, NTP42-treated animals displayed a loose, open network of lung tissue with normal alveolar wall thickness (Fig. 3a). In these NTP42-treated animals, there was a very low degree of vascular remodelling present with only small numbers of sites of substantial inflammatory infiltration present (Fig. 3b).

In order to quantify the observed extent of vascular remodelling, detailed morphometric analyses of the pulmonary arterioles in lung tissues was performed across all animals and treatment groups. These morphometric analyses confirmed that MCT treatment led to substantial worsening relative to the 'No MCT' animal group in the three parameters reported by this approach, namely, lumen:total vessel diameter ratio, medial thickness, and degree of vessel occlusion (Fig. 4). Notably, this significant vascular remodelling was observed in groupings of either all vessels $>15 \mu \mathrm{m}$ in size $(P<0.0001, P=0.0002$ and $P<0.0001$, respectively; Fig. $4 \mathrm{a}-\mathrm{c})$ or in a grouping of small $(>15 \mu \mathrm{m}$ and $\leq 50 \mu \mathrm{m})$ pulmonary arterioles only (all $P<0.0001$; Fig. 4d-f). 


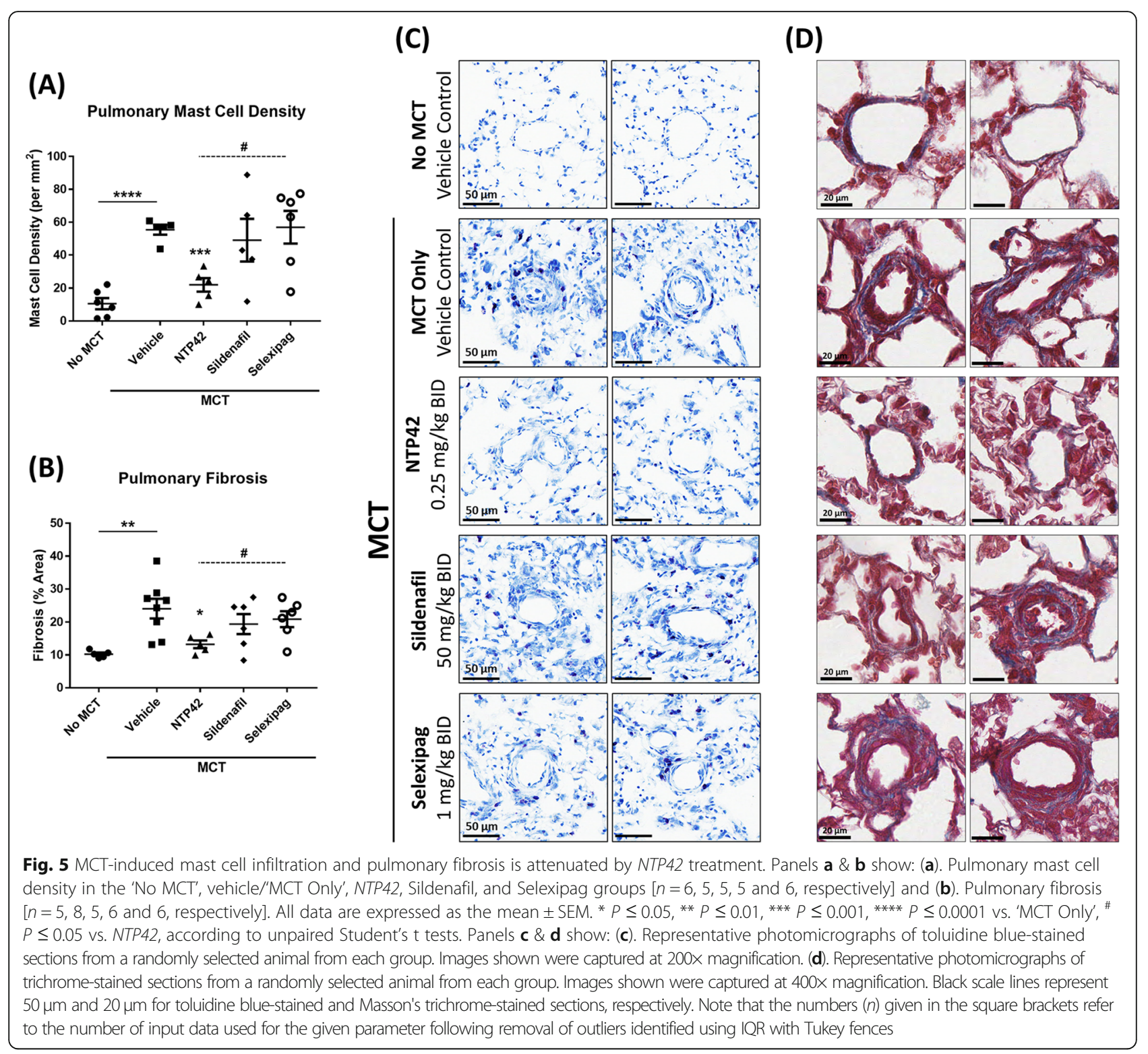

Treatment with NTP42 significantly attenuated both the MCT-induced decrease in lumen:total vessel diameter ratio and the MCT-induced increase in the degree of vessel occlusion $(\mathrm{P}<0.0001$, in all cases; Fig. 4a \& c). Similarly, treatment with Sildenafil also led to improvements in these parameters relative to the 'MCT Only' control $(P=0.0152$ and $P=0.0148$, respectively; Fig. 4a \& c). Improvements in these pulmonary vascular remodelling parameters were also observed for both NTP42- and Sildenafil-treated animals in small vessels only (Fig. 4d \& f). Notably, while showing a varying degree of improvement, treatment with Selexipag did not lead to significant changes in either the lumen:total vessel diameter ratio or the degree of vessel occlusion, relative to the
'MCT Only' controls $(P=0.3976$ and $P=0.3873$, respectively; Fig. 4a \& c).

In parallel and consistent with these effects, morphometric analysis also confirmed that the MCT-induced increase in the medial thickness of pulmonary arterioles was significantly reduced in MCT-treated animals following treatment with NTP42 $(P<0.0001)$, but not following treatment with either Sildenafil or Selexipag (Fig. 4b \& e). Moreover, the medial thickness observed following treatment with NTP42 was significantly reduced relative to both Sildenafil- and Selexipag-treated animals ( $P=0.0302$ and $P=0.0018$, respectively; Fig. $4 \mathrm{~b})$.

Hence, these data strongly support the efficacy of NTP42 in reducing pulmonary vascular remodelling, and that it is superior to Sildenafil in bringing about these 
effects, clearly highlighting the potential significant benefits of NTP42 relative to the standard-of-care reference drugs Sildenafil or Selexipag.

\section{Effect of NTP42 on pulmonary inflammation and fibrosis}

There is growing evidence of the diverse role for inflammatory processes and cell-mediated immunity in the pathogenesis of $\mathrm{PAH}$ and indeed other pulmonary conditions [23]. Of the various immune cells that have been implicated in PAH, mast cells were among the first suggested to potentially play a key role in its pathophysiology, strongly contributing to vascular remodelling and leading to pulmonary fibrosis. As such, modulators of mast cells and mast cell-derived mediators may present promising targets for the treatment of lung diseases such as PAH [24]. To evaluate the effect of NTP42 treatment on mast cell recruitment and the development of pulmonary fibrosis, lung tissues were stained with toluidine blue and Masson's trichrome to quantity mast cell density and determine collagen deposition, respectively. Results are shown in Fig. 5.

After staining with toluidine blue, lung sections from animals in the 'MCT Only' group showed a significantly elevated mast cell density relative to those from the 'No MCT' group ( $\mathrm{P}<0.0001$; Fig. 5a). Similarly, after staining with Masson's trichrome, the percentage fibrotic area in the lungs of animals treated with 'MCT Only' was significantly increased compared to those from the 'No MCT' group ( $P=0.0040$; Fig. $5 b)$. As displayed in representative photomicrographs in Fig. $5 \mathrm{c} \& \mathrm{~d}$, mast cell recruitment and pulmonary fibrosis in the 'MCT Only' group were most pronounced in the immediate vicinity of small pulmonary arterioles.

Treatment with NTP42 significantly attenuated both the MCT-induced increase in mast cell density and percentage fibrotic area $(P=0.0002$ and $P=0.0180$, respectively; Fig. 5a \& c). Notably, of the treatments assessed in this study, NTP42 was the only agent that led to significant and substantial decreases in these parameters. In contrast, treatment with either Sildenafil or Selexipag produced less noticeable changes in the MCT-induced increase in mast cell density and percentage fibrotic area within the lungs of animals treated with these compounds (Fig. 5a \& c).

Representative photomicrographs in Fig. 5c \& d, with a focus around vascular beds, show a noticeably more pronounced mast cell recruitment and collagen deposition in animals treated with either Sildenafil or Selexipag, compared to those in the NTP42-treated group. Furthermore, and in line with the histological assessments and morphometric analyses performed previously (Figs. $3 \& 4$ ), pulmonary vascular remodelling in NTP42-treated animals appears noticeably reduced relative to the 'MCT Only' controls, and indeed relative to the Sildenafil- and Selexipag-treated animal groups.

\section{Discussion}

Treatment of PAH has primarily focused on correcting imbalances between the multiple vasodilator and vasoconstrictor pathways in the pulmonary circulation that results in haemodynamic abnormalities including elevated pulmonary arterial pressure (PAP) and increasing pulmonary vascular resistance (PVR). Unfortunately, currently approved therapies are often short-acting, exhibit limited efficacy at modifying or preventing disease progression, and many have side effects. While the goals of current treatments are to achieve increased exercise capacity, improved quality of life, and to slow disease progression and lower mortality risk, none of the currently-approved therapies have been shown to slow pathological progression [25]. PAH remains an incurable condition with a high mortality rate, underscoring the need for new drugs to new therapeutic targets that will offer greater overall efficacy and tolerability/compliance [26].

$\mathrm{TXA}_{2}$, as a potent vasoconstrictor, inducer of platelet aggregation and smooth muscle constrictor and mitogen, has drawn significant attention as a potential therapeutic target for PAH. Several lines of evidence implicate the $\mathrm{TXA}_{2}-\mathrm{TP}$ axis as a contributor to $\mathrm{PAH}$, and indeed in other classes of pulmonary hypertension. The importance of $\mathrm{TXA}_{2}$ as a driver of disease pathology is indicated by findings in paediatric patients with PAH caused by congenital heart disease defects. These patients typically have elevated urinary and plasma levels of thromboxane (TX) $B_{2}$, the stable end-product metabolite of $\mathrm{TXA}_{2}$ [27]. In infants with persistent pulmonary hypertension of the newborn (PPHN), elevated levels of $\mathrm{TXB}_{2}$ positively correlated with a significantly increased pulmonary artery pressures [28]. Furthermore, in adult PAH patients, 24-h excretion levels of $\mathrm{TXB}_{2}$ are increased, as compared with normal controls, whereas, in contrast, 24-h excretion of 2,3-dinor-6-keto-prostaglandin $F_{1 \alpha}$ (a stable metabolite of prostacyclin) are significantly decreased [29]. Results from a recent randomised clinical trial of Aspirin and Simvastatin (ASA-STAT) showed that PAH patients with higher levels of $\mathrm{TXA}_{2}$ were associated with more advanced disease, and with worse clinical outcome/survival [30]. With regards to the TP, employing radioligand binding studies, its expression was shown to be significantly elevated in the right ventricles (RVs) from PAH patients compared to non-diseased controls [31]. Additionally, while expression in normal RV was found to be primarily perinuclear, the TP was strongly expressed throughout the cell surface in cardiomyocytes of patients with PAH [32].

Expanding on the growing evidence for the role for the TP in $\mathrm{PAH}$, this current study demonstrated 
abundant expression of both TP $\alpha$ and TP $\beta$ isoforms of the TP in the human lung, both in normal control and $\mathrm{PAH}$ disease tissues. Thereafter, this study demonstrated, for the first time, that TP antagonism by treatment with the novel TP antagonist NTP42 prevented the development of $\mathrm{PAH}$ and ameliorated its progression in the MCT-preclinical model of PAH in rodents. NTP42 reduced $\mathrm{MCT}$-induced $\mathrm{PAH}$ as determined from the haemodynamic measurements, and at least to a similar extent as the standard-of-care drug Sildenafil or Selexipag. Moreover, detailed morphometric analysis of pulmonary vascular remodelling and histological analysis of inflammation and fibrosis indicate that the TP antagonist NTP42 was superior to Sildenafil and Selexipag in reducing the vascular remodelling, mast cell recruitment and pulmonary collagen deposition in the MCT-treated animals. From a histological assessment, lung tissue from NTP42-treated animals and 'No MCT' control animals displayed similar histochemistry across the various parameters analysed (i.e., alveolar wall thickening, gas exchange distances, inflammatory infiltrates, vessel remodelling) which, in turn, was radically different and more pronouncedly diseased in 'MCT Only'-, Sildenafiland Selexipag-treated animals. These findings illustrate a significant benefit of NTP42 compared with the approved drugs Sildenafil and Selexipag in lung pathology/ histology outcomes. Notably, in the current study, NTP42 shows at least equivalent haemodynamic outcomes or significantly greater lung histology/pathology benefit than Sildenafil even when NTP42 $(0.25 \mathrm{mg} / \mathrm{kg}$ BID, PO) was used at a 200-fold lower dosage than Sildenafil (50 mg/kg BID, PO).

While similar haemodynamic benefits were observed for NTP42 in comparison to both Sildenafil and Selexipag in alleviating the MCT-induced increase in mPAP, and where NTP42 and Sildenafil, but not Selexipag, treatment resulted in decreases in RVSP, it was highly notable that TP antagonism via NTP42 was the only treatment that showed significant decreases in pulmonary mast cell infiltration and fibrosis. Whereas mast cells have traditionally been recognised as critical in allergic and nonallergic immune responses, a growing body of evidence implicates these cells in cardiovascular disease, including in PAH. Mast cell infiltration around small pulmonary vessels has been noted in models of pulmonary hypertension, and indeed within plexiform lesions of PAH patients [33]. They also stimulate the proliferation of endothelial and smooth muscle cells $[34,35]$. Through their release of histamine, heparin and chymase as well as multiple other molecules, mast cells contribute strongly to pro-fibrotic activities, either directly through effects on fibroblasts and fibrocytes, or indirectly through the recruitment and activation of various inflammatory and structural cell types [36]. Additionally, and of particular relevance to this study, activated mast cells produce significant quantities of $\mathrm{TXA}_{2}$, alongside other prostanoids [37]. Taken together, these previous findings consolidate the hypothesis that mast cells may contribute to the pathogenesis of PAH. The effect of NTP42 in reducing mast cell recruitment within the lung, and the potential resulting pulmonary fibrosis, is of particular note and demonstrates a unique benefit of TP antagonism in this study, at least. While deemed beyond the scope of the current study, it will be of interest to explore how NTP42 may impact on other pathways within the innate and/or adaptive immune systems. Furthermore, it must be noted that while toluidine blue is a routinely-used stain for mast cells within the tissues of animals from MCT-PAH investigations [38-40], additional specific markers such as c-Kit/CD117 may be employed in future studies as a further validation of the effect of TP antagonism on mast cell recruitment.

Previous investigations have attempted to clinically assess the effects of disrupting the $\mathrm{TXA}_{2}$-TP axis in the treatment of $\mathrm{PAH}$. Inhibition of $\mathrm{TXA}_{2}$ production using the $\mathrm{TXA}_{2}$ synthase $\left(\mathrm{TXA}_{2} \mathrm{~S}\right)$ inhibitor CGS13080 resulted in a modest improvement in pulmonary haemodynamics in a small study of patients with PAH [41]. Showing promise in preclinical investigations, the dual $\mathrm{TXA}_{2} \mathrm{~S}$ inhibitor/TP antagonist terbogrel prevented pulmonary hypertension and the development of pulmonary artery dysfunction in a chronic hypoxia-induced porcine pulmonary hypertension model [42]. However, a multicentre, randomised, placebo-controlled Phase II trial of terbogrel for use in adults with PAH had to be terminated prematurely because of severe leg pain, which occurred almost exclusively in terbogrel-treated patients [43]. As a $\mathrm{TXA}_{2} \mathrm{~S}$ inhibitor, while terbogrel was pharmacologically effective in reducing $\mathrm{TXA}_{2}$ metabolites, it also led to a rise in levels of prostacyclin metabolites [43]. In PAH patients, prostacyclin-associated leg pain is a recognised debilitating adverse effect in PAH patients on prostacyclin therapy [44]. In follow-up pharmacokinetic and pharmacodynamic assessments, treatment with terbogrel across a range of doses resulted in up to 10fold increases in prostacyclin metabolites [45]. Thus, it is now widely accepted that inhibiting $\mathrm{TXA}_{2}$ synthesis, either through the administration of selective $\mathrm{TXA}_{2} \mathrm{~S}$ inhibitor or dual $\mathrm{TXA}_{2} \mathrm{~S}$ inhibitor/TP antagonist compounds, shifts the enzymatic conversion of the common precursor endoperoxide substrates $\mathrm{PGG}_{2} / \mathrm{PGH}_{2}$ away from $\mathrm{TXA}_{2}$ biosynthesis towards generation of the pain/ nociceptive-inducing prostacyclin [43].

Bearing in mind these side-effects associated with increases in prostacyclin levels as a result of $\mathrm{TXA}_{2} \mathrm{~S}$ inhibition, it is crucial that any proposed inhibitor of the $\mathrm{TXA}_{2}$-TP signalling axis have a positive drug profile and yet retain the ability to ameliorate the development of PAH. NTP42 is a highly potent and selective TP 
antagonist with efficacy in the low nanomolar range (Supplemental Figures 1 \& 2). Specifically, NTP42 antagonised intracellular calcium mobilization following stimulation of mammalian HEK 293 cells stably over-expressing the TP $\beta$ isoform of the human TP (HEK.TP $\beta$ line) with the $\mathrm{TXA}_{2}$ mimetic U46619 ( $\mathrm{IC}_{50} 8.86 \pm 3.07 \mathrm{nM}$; Supplemental Figure 1A). Furthermore, and as previously discussed, as a highly specific antagonist of the TP, NTP42 will directly inhibit the actions of the isoprostane 8-iso$\mathrm{PGF}_{2 \alpha}$, which can exert pulmonary hypertensive effects in several distinct ways [46]. Herein, NTP42 antagonised intracellular calcium mobilization in the HEK.TP $\beta$ line following stimulation with 8 -iso- $\mathrm{PGF}_{2 \alpha}\left(\mathrm{IC}_{50} 8.04 \pm 3.74\right.$ $\mathrm{nM}$; Supplemental Figure 1B). NTP42 was also shown to antagonize U46619-induced aggregation of human platelets, where NTP42 was confirmed to have an $\mathrm{IC}_{50}$ of $10.6 \pm 1.7 \mathrm{nM}$ (Supplemental Figure 2). In the context of TP specificity, NTP42 was confirmed to be an entirely selective TP antagonist, with no agonist actions at the TP (Supplemental Figure 3). Specifically, NTP42 was assessed for activity at the 7 other prostanoid receptors, namely the prostaglandin (PG) $\mathrm{D}_{2}\left(\mathrm{DP}_{1}\right), \mathrm{PGE}_{2}\left(\mathrm{EP}_{1}, \mathrm{EP}_{2}, \mathrm{EP}_{3}, \mathrm{EP}_{4}\right)$, $\mathrm{PGF}_{2 \alpha}(\mathrm{FP})$ and $\mathrm{PGI}_{2} /$ prostacyclin (IP) prostanoid receptors, and was confirmed to exhibit no agonist or antagonist effects at these receptors (Supplemental Figure 3 \& Supplemental Table 2). Furthermore, unlike the dual $\mathrm{TXA}_{2} \mathrm{~S}$ inhibitor/TP antagonist terbogrel, NTP42 does not inhibit $\mathrm{TXA}_{2} \mathrm{~S}$ (Supplemental Figure 4). Thus, in contrast to terbogrel which, as stated, has been clinically evaluated for efficacy in PAH [43], NTP42 is a selective TP antagonist and does not affect levels of the nociceptive agent prostacyclin.

\section{Limitations of study}

Based on the choice of the PAH preclinical model, several limitations with the current study must be acknowledged. In the case of the MCT-PAH model, animals respond to a single administration of the highly toxic pyrrolizidine alkaloid MCT and the disease develops quickly where even within $6 \mathrm{~h}$ post-MCT administration, changes associated with disease induction can be observed. Thereafter, over a period of 1-2 weeks, PAH develops and without any drug intervention, a high proportion of animals typically succumb to the disease through death or animals must be sacrificed due to morbidity concerns [47]. Thus, owing to the relatively rapid development and progression of the disease, the MCTinduced PAH model is frequently best employed as a prophylactic or early intervention model where the test drug is administered either simultaneously with the MCT or within a short duration post-MCT induction, as was the case in this study. The therapeutic effects of NTP42 should therefore be further investigated using conditions viewed as more reminiscent of a treatment model, rather than a prophylactic model. This could be achieved within the MCT-induced PAH model by

\section{Roles for the TP in mediating PAH

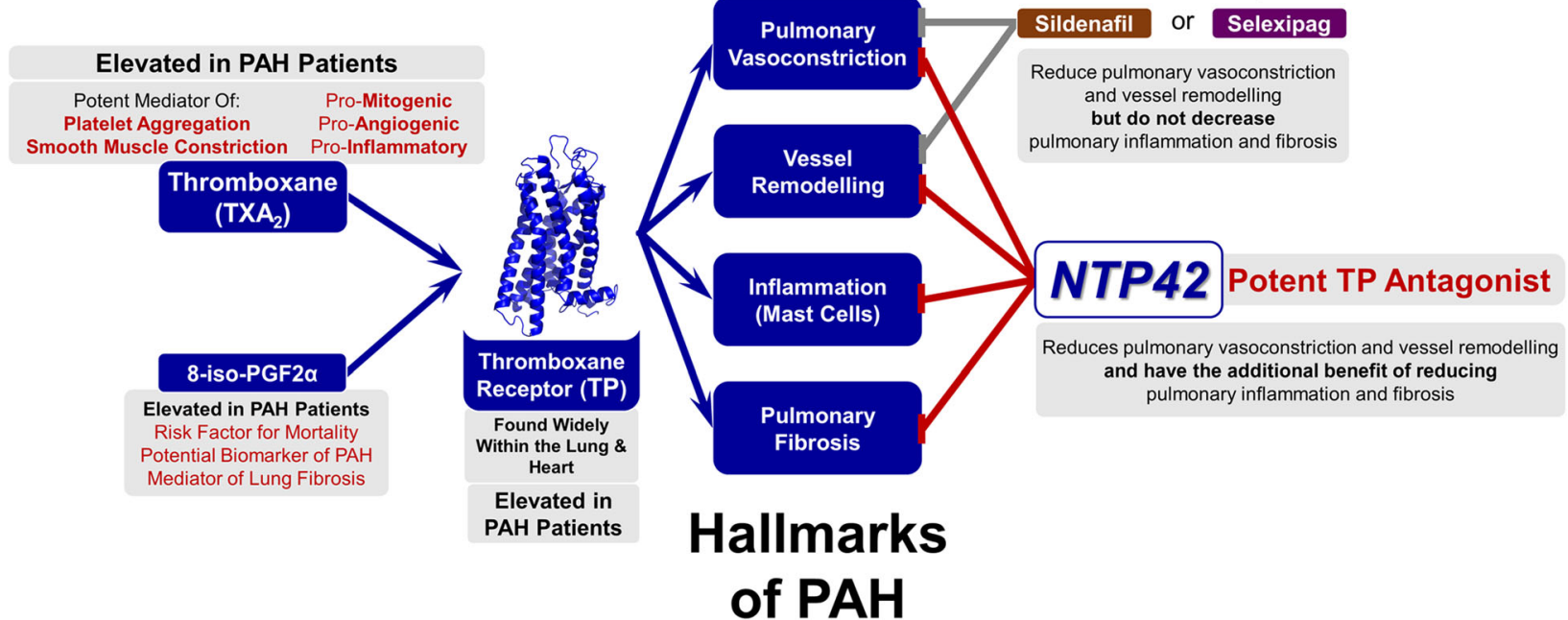

Fig. 6 TP antagonism using NTP42 alleviates key hallmarks associated with PAH. The thromboxane receptor (TP) is a key driver of pulmonary arterial hypertension (PAH). Signalling through the TP, the cyclooxygenase-derived prostanoid thromboxane (TX) $A_{2}$ and free-radical induced isoprostane 8-iso-prostaglandin $(P G) F_{2 a}$ both elicit profound effects that contribute to the pathology of PAH, including vasoconstriction and endothelial and smooth muscle cell hyperproliferation, pulmonary vascular remodelling, inflammation, fibrosis, and thrombosis. Within this preclinical study, NTP42 reduced MCT-induced PAH as determined from the haemodynamic measurements, and at least to a similar extent as the standard-of-care drug Sildenafil or Selexipag. Moreover, NTP42 was superior to Sildenafil and Selexipag in reducing the vascular remodelling, mast cell recruitment and pulmonary collagen deposition in the MCT-treated animals. Based on these findings, blockade of the TP using NTP42 is predicted to alleviate the pathophysiology of PAH, representing a novel therapeutic target with marked benefits over existing therapies 
delaying treatment with NTP42 to strike a balance between undue loss of animals due to high mortality rates versus definitively demonstrating treatment of the disease. Alternatively, and in line with recent industry recommendations [48], the therapeutic effects of NTP42 should be investigated using a second distinct preclinical model, such as the Sugen 5416/hypoxia ( $\mathrm{SuHx}$ )-induced PAH model. While both the MCT model and the SuHx model are widely reported to emulate $\mathrm{PAH}$, they each display features both typical and atypical of the human disease and of each other [47, 49-51]. For example, a key distinguishing feature between the $\mathrm{SuHx}$ and MCTinduced PAH models is the formation of occlusive neointimal or plexiform lesions, which are characteristic of the advanced lesions seen in PAH patients associated with the former, and widely associated with advanced cases of the human condition, but which is absent in the MCT-PAH model [47, 49-51]. On the other hand, inflammation appears to be a key component of the disease that develops in the MCT-model, a feature that is less of a burden in the human PAH lung and that is virtually absent in the SuHx model [47, 49-51].

Notwithstanding the significance of the findings of this study, it should also be acknowledged that the level of the MCT-induced disease, as demonstrated by the low but consistent increase in mPAP, RVSP and Fulton's Index, was not as severe when compared with previous studies $[52,53]$. It is acknowledged that the level of PAH disease induced by MCT administration can vary significantly across species, strains and individual animals $[51,54]$. The more moderate $\mathrm{PH}$ induced in this model may account for the lack of significant benefit observed for NTP42 in the Fulton's Index parameter, and for the lack of benefit observed for Selexipag in the RVSP and Fulton's Index parameter. Notably, the Selexipag animal group size was lower than the other treatment groups investigated, and this may also have had an effect on the statistical findings. Future preclinical investigations should be performed under more severe disease conditions, to further highlight the potential benefits of NTP42 or indeed, of the comparator standard-of-care treatments.

A further acknowledged limitation of this study was that while NTP42 treatment led to reductions in RVSP relative to the 'MCT Only' control, no significant changes were observed in RV hypertrophy, as assessed through measurement of the Fulton's Index. In an additional follow-up study primarily focussing on the effect of NTP42 on cardiac hypertrophy, NTP42 treatment at $0.125 \mathrm{mg} / \mathrm{kg}$ QD significantly decreased the MCT-induced rise in the Fulton's Index (Supplemental Figure 5A). In additional assessments of cardiac hypertrophy within this experimental cohort, RV tissues were stained with anti-CD31 antibody (Supplemental Figure 5B) which enabled autologous quantitation of both CD31 positive vascular endothelial cells, a measure of vascularization/angiogenesis, and also of cardiomyocyte cross-sectional area, a measure of cardiac hypertrophy. Thus, measurement of these two parameters (i) cardiomyocyte cross-sectional area and (ii) vascularisation per unit area provides a direct assessment of 'metabolic demand' and 'metabolic supply', respectively, within the RV tissue and when expressed as a ratio, can be used as a measure, so-called Metabolic Index, of 'Maladaptive hypertrophy' (where ratio of (i)/(ii) is $>1$ ) or 'Adaptive hypertrophy' (where ratio of (i)/(ii) is $<1$ ). In accordance with the Fulton's Index (Supplemental Figure 5A) findings, treatment with NTP42 at $0.125 \mathrm{mg} / \mathrm{kg}$ QD led to a significant decrease in cardiomyocyte cross-sectional area (Supplemental Figure 5C). While treatment with NTP42 at this dose had no significant effect on RV vascularization per se (Supplemental Figure 5D), considering both RV hypertrophy and vascularisation together within a "Metabolic Index" parameter, treatment with NTP42 led to a significant increase in this indicative parameter of cardiac adaptation (Supplemental Figure 5E). Finally, the progress observed in the clinical management of PAH has been largely attributed to the development of combination therapy strategies, and on the staggered escalation of those dual- or even triplecombination therapies based on close monitoring and assessment of clinical outcomes in line with established treatment algorithms [55-57]. Consistent with these clinical guidelines, it will be important to assess the efficacy of NTP42 alongside other therapies such as PDE5 inhibitors (e.g. Sildenafil), prostacyclin analogues (e.g. Selexipag) or members of the ERA class of PAH treatments.

\section{Conclusions}

In conclusion, and as summarised in Fig. 6, multiple lines of evidence demonstrate the potential importance of $\mathrm{TXA}_{2}$ and 8-iso- $\mathrm{PGF}_{2 \alpha}$, signalling through the TP, as key drivers in the development and progression of $\mathrm{PAH}$, and indeed other classes of pulmonary hypertension. The inhibition of TP signalling by the potent and specific TP antagonist NTP42 ameliorated the development of PAH over a range of disease-indicating parameters in the MCT-induced preclinical animal model. Uniquely, TP antagonism by NTP42 led to marked decreases in pulmonary inflammation and fibrosis, hallmarks of $\mathrm{PAH}$ pathology which were not alleviated by the other standard-of-care PAH therapies considered within this study. Based on improved efficacy over the spectrum of these disease parameters, NTP42 is expected to show significantly improved benefits over Sildenafil and Selexipag in the treatment of PAH. Therefore, TP antagonism, such as through the use of NTP42 is suggested to be a novel therapeutic strategy for the treatment of $\mathrm{PAH}$, with a distinct mechanism of action specifically targeting the pulmonary circulation and alleviating multiple key hallmarks of PAH. 


\section{Supplementary information}

Supplementary information accompanies this paper at https://doi.org/10. 1186/s12890-020-1113-2.

Additional file 1. Supplementary Methods, Supplementary Tables 1 \& $\mathbf{2}$ and Supplementary Figures 1-5

\section{Abbreviations}

8-iso-PGF 2a: 8-iso-prostaglandin $\mathrm{F}_{2 a i}$ AA: Arachidonic acid; CO: Cardiac output; COX: Cyclooxygenase; EC: Endothelial cell; ERA: Endothelin receptor antagonist; FFPE: Formalin-fixed paraffin-embedded; H\&E: Haematoxylin and eosin; HR: Heart rate; IP: I prostanoid/prostacyclin receptor; IQR: Interquartile range; mAP: mean systemic arterial pressure; MCT: Monocrotaline; mPAP: mean pulmonary arterial pressure; NO: Nitric oxide; PAH: Pulmonary arterial hypertension; PAP: Pulmonary arterial pressure;

PDI: Phosphodiesterase type 5 inhibitor; PVR: Pulmonary vascular resistance; RV: Right ventricle; RVSP: Right systolic ventricular pressure; SEM: Standard error of the mean; sGC: soluble guanylyl cyclase; SM: Smooth muscle; SMC: Smooth muscle cell; SuHx: Sugen 5416/hypoxia; TP: Thromboxane

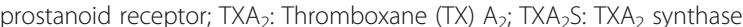

\section{Acknowledgements}

We are grateful to Marie Chet Malgapo, Tissue Bank Co-ordinator at the Papworth Hospital NHS Foundation Trust for facilitating access to the human lung tissue used in this study.

\section{Authors' contributions}

$E M, H R, A B, D S$ and BTK designed the experiments. EM, HR, LB and $A B$ performed the experiments. EM, HR, LB, AB, DS and BTK analysed and interpreted data. EM and BTK wrote the manuscript. All authors were involved in critically revising the manuscript. The authors read and approved the final manuscript

\section{Funding}

This work was supported by funding from Enterprise Ireland, Commercialisation Fund Programme [Project Numbers: CFTD/2009/0122 \& CF/2012/2608] and from the European Commission, Horizon 2020 SME Instrument [Project Number: 822258]. These funding sources supported ATXA Therapeutics' research and development programme and the individual funding bodies did not play a role in the study design, data collection, data analysis, data interpretation or in writing the manuscript.

\section{Availability of data and materials}

The datasets used and/or analysed during the current study are available from the corresponding author on reasonable request.

\section{Ethics approval and consent to participate}

All animal studies were performed at the facilities of IPS Therapeutique (IPST; Sherbrooke, Quebec, Canada). The institutional animal ethics committee of IPST approved the studies in strict accordance with the guidelines of the Canadian Council on Animal Care and the US NIH Guide for the Care and Use of Laboratory Animals. Human lung tissue was obtained from the Royal Papworth Hospital NHS Foundation Trust Tissue Bank (Cambridge, UK). Written consent was obtained for all tissue samples using Royal Papworth Hospital NHS Foundation Trust Tissue Bank's ethical approval (East of England - Cambridge East Research Ethics Committee 08/H0304/56 + 5).

\section{Consent for publication}

Not applicable.

\section{Competing interests}

EPM, HMR, LB and BTK are employees of ATXA Therapeutics Ltd. BTK is also a member of the board of directors of ATXA Therapeutics $L t d$. The authors EPM, HMR, LB and BTK declare that they have no competing interests. AB and DS were employees of IPS Therapeutique Inc. at the time of conducting the work reported in this manuscript. This work was sponsored by ATXA Therapeutics Ltd. The authors AB and DS certify that they have no affiliations with, or involvement in, any organisation or entity with any financial or nonfinancial interest in the subject matter or materials discussed in this manuscript.

\section{Author details}

ATXA Therapeutics Limited, UCD Conway Institute of Biomolecular and Biomedical Research, University College Dublin, Belfield, Dublin 4, Ireland. ${ }^{2}$ UCD School of Biomolecular and Biomedical Sciences, UCD Conway Institute of Biomolecular and Biomedical Research, University College Dublin, Belfield, Dublin 4, Ireland. 'IPS Therapeutique Inc., 3035 Boulevard Industriel, Sherbrooke, QC J1L 2T9, Canada.

Received: 28 November 2019 Accepted: 12 March 2020

Published online: 06 April 2020

\section{References}

1. Simonneau G, Montani D, Celermajer DS, Denton CP, Gatzoulis MA, Krowka $M$, et al. Haemodynamic definitions and updated clinical classification of pulmonary hypertension. Eur Respir J. 2019:53:1.

2. Capra V, Busnelli M, Perenna A, Ambrosio M, Accomazzo MR, Gales C, et al. Full and partial agonists of thromboxane prostanoid receptor unveil fine tuning of receptor superactive conformation and g protein activation. PLoS One. 2013;8(3):e60475.

3. Davi G, Santilli F, Vazzana N. Thromboxane receptors antagonists and/or synthase inhibitors. Handb Exp Pharmacol. 2012;210:261-86.

4. Devillier P, Bessard G. Thromboxane A2 and related prostaglandins in airways. Fundam Clin Pharmacol. 1997;11(1):2-18.

5. Ekambaram P, Lambiv W, Cazzolli R, Ashton AW, Honn KV. The thromboxane synthase and receptor signaling pathway in cancer: an emerging paradigm in cancer progression and metastasis. Cancer Metastasis Rev. 2011;30(3-4):397-408.

6. Mulvaney EP, Shilling C, Eivers SB, Perry AS, Bjartell A, Kay EW, et al. Expression of the TPalpha and TPbeta isoforms of the thromboxane prostanoid receptor (TP) in prostate cancer: clinical significance and diagnostic potential. Oncotarget. 2016;7(45):73171-87.

7. O'Sullivan AG, Mulvaney EP, Hyland PB, Kinsella BT. Protein kinase C-related kinase 1 and 2 play an essential role in thromboxane-mediated neoplastic responses in prostate Cancer. Oncotarget. 2015;6(28):26437-56.

8. O'Sullivan AG, Eivers SB, Mulvaney EP, Kinsella BT. Regulated expression of the TPbeta isoform of the human T prostanoid receptor by the tumour suppressors FOXP1 and NKX3.1: implications for the role of thromboxane in prostate cancer. Biochim Biophys Acta. 2017;1863(12):3153-69.

9. Bauer J, Ripperger A, Frantz S, Ergun S, Schwedhelm E, Benndorf RA. Pathophysiology of isoprostanes in the cardiovascular system: implications of isoprostane-mediated thromboxane $\mathrm{A} 2$ receptor activation. $\mathrm{Br}$ J Pharmacol. 2014;171(13):3115-31.

10. Zhang $R$, Sun ML, Fan YF, Jiang X, Zhao QH, He J, et al. Plasma 15-F2tisoprostane in idiopathic pulmonary arterial hypertension. Int J Cardiol. 2014;175(2):268-73.

11. Arezzini B, Vecchio D, Signorini C, Stringa B, Gardi C. F2-isoprostanes can mediate bleomycin-induced lung fibrosis. Free Radic Biol Med. 2018; 115(Supplement C):1-9.

12. Roehl $A B$, Steendijk P, Baumert JH, Schnoor J, Rossaint R, Hein M Comparison of 3 methods to induce acute pulmonary hypertension in pigs. Comp Med. 2009;59(3):280-6.

13. Rothman AM, Arnold ND, Chang W, Watson O, Swift AJ, Condliffe R, et al. Pulmonary artery denervation reduces pulmonary artery pressure and induces histological changes in an acute porcine model of pulmonary hypertension. Circ Cardiovasc Interv. 2015:8(11):e002569.

14. Bonnell MR, Urdaneta F, Kirby DS, Valdez NR, Beaver TM, Lobato EB. Effects of sildenafil analogue UK 343-664 on a porcine model of acute pulmonary hypertension. Ann Thorac Surg. 2004;77(1):238-42.

15. Kylhammar D, Radegran G. Cyclooxygenase-2 inhibition and thromboxane a (2) receptor antagonism attenuate hypoxic pulmonary vasoconstriction in a porcine model. Acta Physiol (Oxford). 2012;205(4):507-19.

16. Kinsella BT, Reid HM. (inventors) Thromboxane receptor antagonists patent U.S. Patent No. 10,357,504. June 13; 2016

17. Kinsella BT, Reid HM. (inventors) Thromboxane receptor antagonists patent U.S. Patent No. 9,932,304. June 16; 2015

18. Bankhead $P$, Loughrey MB, Fernandez JA, Dombrowski Y, McArt DG, Dunne PD, et al. QuPath: open source software for digital pathology image analysis. Sci Rep. 2017:7(1):16878.

19. Schermuly RT, Dony E, Ghofrani HA, Pullamsetti S, Savai R, Roth M, et al. Reversal of experimental pulmonary hypertension by PDGF inhibition. J Clin Invest. 2005;115(10):2811-21. 
20. Schindelin J, Rueden CT, Hiner MC, Eliceiri KW. The ImageJ ecosystem: an open platform for biomedical image analysis. Mol Reprod Dev. 2015;82(7-8): 518-29.

21. Ruifrok AC, Johnston DA. Quantification of histochemical staining by color deconvolution. Anal Quant Cytol Histol. 2001;23(4):291-9.

22. St Croix CM, Steinhorn RH. New thoughts about the origin of Plexiform lesions. Am J Respir Crit Care Med. 2016;193(5):484-5.

23. Rabinovitch M, Guignabert C, Humbert M, Nicolls MR. Inflammation and immunity in the pathogenesis of pulmonary arterial hypertension. Circ Res. 2014;115(1):165-75.

24. Xu J, Wang J, Shao C, Zeng X, Sun L, Kong H, et al. New dynamic viewing of mast cells in pulmonary arterial hypertension (PAH): contributors or outsiders to cardiovascular remodeling. J Thorac Dis. 2018;10(5):3016-26.

25. Thenappan T, Ormiston ML, Ryan JJ, Archer SL. Pulmonary arterial hypertension: pathogenesis and clinical management. BMJ. 2018;360:j5492.

26. Huetsch JC, Suresh K, Bernier M, Shimoda LA. Update on novel targets and potential treatment avenues in pulmonary hypertension. Am J Phys Lung Cell Mol Phys. 2016;311(5):L811-L31.

27. Fuse S, Kamiya T. Plasma thromboxane B2 concentration in pulmonary hypertension associated with congenital heart disease. Circulation. 1994; 90(6):2952-5.

28. Bui KC, Hammerman C, Hirschl R, Snedecor SM, Cheng KJ, Chan L, et al. Plasma prostanoids in neonatal extracorporeal membrane oxygenation. Influence of meconium aspiration. J Thorac Cardiovasc Surg. 1991;101(4):612-7.

29. Christman BW, McPherson CD, Newman JH, King GA, Bernard GR, Groves $\mathrm{BM}$, et al. An imbalance between the excretion of thromboxane and prostacyclin metabolites in pulmonary hypertension. N Engl J Med. 1992; 327(2):70-5.

30. Al-Naamani N, Palevsky HI, Lederer DJ, Horn EM, Mathai SC, Roberts KE, et al. Prognostic significance of biomarkers in pulmonary arterial hypertension. Ann Am Thorac Soc. 2016;13(1):25-30.

31. Katugampola SD, Davenport AP. Thromboxane receptor density is increased in human cardiovascular disease with evidence for inhibition at therapeutic concentrations by the AT (1) receptor antagonist losartan. Br J Pharmacol. 2001;134(7):1385-92.

32. West JD, Voss BM, Pavliv L, de Caestecker M, Hemnes AR, Carrier EJ. Antagonism of the thromboxane-prostanoid receptor is cardioprotective against right ventricular pressure overload. Pulm Circ. 2016;6(2):211-23.

33. Farha S, Sharp J, Asosingh K, Park M, Comhair SA, Tang WH, et al. Mast cell number, phenotype, and function in human pulmonary arterial hypertension. Pulm Circ. 2012;2(2):220-8.

34. Marks RM, Roche WR, Czerniecki M, Penny R, Nelson DS. Mast cell granules cause proliferation of human microvascular endothelial cells. Lab Investig. 1986;55(3):289-94

35. Cho SH, Yao Z, Wang SW, Alban RF, Barbers RG, French SW, et al. Regulation of activin a expression in mast cells and asthma: its effect on the proliferation of human airway smooth muscle cells. J Immunol. 2003;170(8): 4045-52.

36. Bradding P, Pejler G. The controversial role of mast cells in fibrosis. Immunol Rev. 2018;282(1):198-231.

37. Morrow JD, Oates JA, Roberts $L J$ 2nd, Zackert WE, Mitchell TA, Lazarus G, et al. Increased formation of thromboxane in vivo in humans with mastocytosis. J Invest Dermatol. 1999;113(1):93-7.

38. Dahal BK, Kosanovic D, Kaulen C, Cornitescu T, Savai R, Hoffmann J, et al. Involvement of mast cells in monocrotaline-induced pulmonary hypertension in rats. Respir Res. 2011;12:60.

39. Hoffmann J, Yin J, Kukucka M, Yin N, Saarikko I, Sterner-Kock A, et al. Mast cells promote lung vascular remodelling in pulmonary hypertension. Eur Respir J. 2011;37(6):1400-10.

40. Luitel H, Sydykov A, Schymura Y, Mamazhakypov A, Janssen W, Pradhan K, et al. Pressure overload leads to an increased accumulation and activity of mast cells in the right ventricle. Phys Rep. 2017;5:6.

41. Rich S, Hart K, Kieras K, Brundage BH. Thromboxane synthetase inhibition in primary pulmonary hypertension. Chest. 1987;91(3):356-60

42. Fike CD, Zhang Y, Kaplowitz MR. Thromboxane inhibition reduces an early stage of chronic hypoxia-induced pulmonary hypertension in piglets. J Appl Physiol (1985). 2005;99(2):670-6.

43. Langleben D, Christman BW, Barst RJ, Dias VC, Galie N, Higenbottam TW, et al. Effects of the thromboxane synthetase inhibitor and receptor antagonist terbogrel in patients with primary pulmonary hypertension. Am Heart J. 2002:143(5):E4

44. Pagani-Estevez GL, Swetz KM, McGoon MD, Frantz RP, Tointon SK, Karnyski AM, et al. Characterization of prostacyclin-associated leg pain in patients with pulmonary arterial hypertension. Ann Am Thorac Soc. 2017;14(2):206-12.

45. Guth BD, Narjes H, Schubert HD, Tanswell P, Riedel A, Nehmiz G. Pharmacokinetics and pharmacodynamics of terbogrel, a combined thromboxane A2 receptor and synthase inhibitor, in healthy subjects. $\mathrm{Br}$ J Clin Pharmacol. 2004;58(1):40-51.

46. Janssen $L$. Isoprostanes and lung vascular pathology. Am J Respir Cell Mol Biol. 2008:39(4):383-9.

47. Gomez-Arroyo JG, Farkas L, Alhussaini AA, Farkas D, Kraskauskas D, Voelkel $\mathrm{NF}$, et al. The monocrotaline model of pulmonary hypertension in perspective. Am J Phys Lung Cell Mol Phys. 2012;302(4):L363-9.

48. Provencher S, Archer SL, Ramirez FD, Hibbert B, Paulin R, Boucherat O, et al. Standards and methodological rigor in pulmonary arterial hypertension preclinical and translational research. Circ Res. 2018;122(7):1021-32.

49. Zhao L. Chronic hypoxia-induced pulmonary hypertension in rat: the best animal model for studying pulmonary vasoconstriction and vascular medial hypertrophy. Drug Discov Today Dis Model. 2010;7(3):83-8.

50. Stenmark KR, Meyrick B, Galie N, Mooi WJ, McMurtry IF. Animal models of pulmonary arterial hypertension: the hope for etiological discovery and pharmacological cure. Am J Phys Lung Cell Mol Phys. 2009;297(6):L1013-32.

51. Colvin KL, Yeager ME. Animal Models of Pulmonary Hypertension: Matching Disease Mechanisms to Etiology of the Human Disease. J Pulm Respir Med. 2014:4:4.

52. Bhat L, Hawkinson J, Cantillon M, Reddy DG, Bhat SR, Laurent CE, et al. RP5063, a novel, multimodal, serotonin receptor modulator, prevents monocrotaline-induced pulmonary arterial hypertension in rats. Eur J Pharmacol. 2017:810:92-9.

53. Kuwano K, Hashino A, Noda K, Kosugi K, Kuwabara K. A long-acting and highly selective prostacyclin receptor agonist prodrug, $2-\{4-[(5,6-$ diphenylpyrazin-2-yl) (isopropyl) amino]butoxy\}-N-(methylsulfonyl) acetam ide (NS-304), ameliorates rat pulmonary hypertension with unique relaxant responses of its active form, \{4-[(5,6-diphenylpyrazin-2-yl) (isopropyl) amino] butoxy\} acetic acid (MRE-269), on rat pulmonary artery. J Pharmacol Exp Ther. 2008:326(3):691-9.

54. Hill NS, Gillespie MN, McMurtry IF. Fifty years of Monocrotaline-induced pulmonary hypertension: what has it meant to the field? Chest. 2017:152(6):1106-8.

55. Galie N, Humbert M, Vachiery JL, Gibbs S, Lang I, Torbicki A, et al. 2015 ESC/ ERS guidelines for the diagnosis and treatment of pulmonary hypertension: the joint task force for the diagnosis and treatment of pulmonary hypertension of the European Society of Cardiology (ESC) and the European Respiratory Society (ERS): endorsed by: Association for European Paediatric and Congenital Cardiology (AEPC), International Society for Heart and Lung Transplantation (ISHLT). Eur Heart J. 2016;37(1):67-119.

56. Klinger JR, Elliott CG, Levine DJ, Bossone E, Duvall L, Fagan K, et al. Therapy for pulmonary arterial hypertension in adults: update of the CHEST guideline and expert panel report. Chest. 2019;155(3):565-86.

57. Hambly N, Alawfi F, Mehta S. Pulmonary hypertension: diagnostic approach and optimal management. CMAJ. 2016;188(11):804-12.

\section{Publisher's Note}

Springer Nature remains neutral with regard to jurisdictional claims in published maps and institutional affiliations.

Ready to submit your research? Choose BMC and benefit from:

- fast, convenient online submission

- thorough peer review by experienced researchers in your field

- rapid publication on acceptance

- support for research data, including large and complex data types

- gold Open Access which fosters wider collaboration and increased citations

- maximum visibility for your research: over $100 \mathrm{M}$ website views per year

At $\mathrm{BMC}$, research is always in progress.

Learn more biomedcentral.com/submissions 